rather too small as turned out by the lathe may be thickly coated and then turned up to the increased diameter required, thus also cbtaining a skin which lasts a very long time. Worn-down tools, bearings, bushes, gauges, valves, and drills can be rendered better than they were when new.

Similar researches have been made with regard to nickel. All buffing and polishing can now be avoided by using a brightening agent in the electrolyte for plating with this metal. The surface can be taken straight out of the bath directly with all the lustre obtainable by polishing, buffing and tumbling. As these processes involve more work than the electroplating itself, the great advantages of the new method are obvious. Other metals, including chromium, are now the subject of research, and it appears more than probable that a high polish in chromium will shortly be obtainable in the same way. Zine, for example, is already being successfully applied with a high polish on emerging from the bath.

\section{Verifying Telephone Subscribers' Numbers}

To avoid the incorrect recording of callers' numbers in a trunk exchange associated with an automatic telephone area, various expedients have been adopted, including the reversion of a certain percentage of originating calls to the use of an audible tone. The supersonic signal method is described in a paper by W. K. Brasher and B. P. Moss (J. Inst. Elect. Eng., July). It was evolved for Palestine, a country in which the us $\ni$ of a number of languages made the problem more acute. It is usual to check a certain number of demand calls either by establishing a second connexion to the subscriber's line, independent of the first, or by 'reverting' the call, that is, recording the particulars of the required number and informing the caller that he will be rung. Both methods lead to delays. Messrs. Brasher and Moss give a full description with diagrams of the method, which is being evolved in Palestine and is now being installed. Demand positions are served by a $20 \mathrm{kc}$. $/ \mathrm{sec}$. oscillator, the output of which can be connected to the operator's telephone circuit of each position. When the demand operator has received the particulars of the wanted and calling subscribers, she passes the call to the distant exchange and moves a dialling plug suitably. The basic principle of the use of a supersonic signal in an automatic telephone exchange has been proved by test to be a practical scheme, no disturbing effect on other circuits having been noticed in a 5,000-line exchange.

\section{The Night Sky in September}

THE moon is new on September 2, whilst full moon (the harvest moon) occurs on September 16. On September 20 at $21 \mathrm{~h}$. and $23 \mathrm{~h}$. U.T. respectively, the moon is in conjunction with Saturn and with Jupiter. Saturn, to which the moon makes the closer approach, may be rather overpowered by the moon's glare. On September 28, a lunar conjunction occurs with Venus. On September 22, an occultation (reappearance) of the 1st magnitude star $\alpha$ Tauri (Aldebaran) may be observed at the moon's dark limb. At Greenwich the reappearance of Aldebaran, then only $9^{\circ}$ above the horizon, is due at about $22 \mathrm{~h} .3 \mathrm{~m}$.; at Edinburgh, where the altitude is more favourable, the time is $22 \mathrm{~h}$. $16 \mathrm{~m}$., at position angle $215^{\circ}$ from the moon's north point. Jupiter and Saturn continue this month as a notable pair of bright planets to be seen throughout the night. On September 16, Saturn souths at $3 \mathrm{~h} .11 \mathrm{~m}$. and Jupiter at $3 \mathrm{~h} .14 \mathrm{~m}$. (add 1 hour to obtain Summer Time). Close groupings of Jupiter's four inner satellites may be seen at 1 . on September 8, 9, 16, 18, 25 and 26. Venus, unmistakable in its brilliancy, also continues as the bright and morning star rising between $1 \mathrm{~h} .12 \mathrm{~m}$. (September 1) to Ih. 50m. (September 30). On the former date, Venus is about midway between Procyon and Castor and Pollux and by the end of the month has moved to a position preceding Regulus. The darkening evenings of September (the autumnal equinox is on September 23) gives unrivalled aspects, when the moon is absent, of the Milky Way near the meridian. The main features of this half of the great stellar structure are easily recognized - the great rift or bifurcation commencing in Cygnus and extending along the galactic equator: the brighter eastern stream with its various star clouds passing southwards through Aquila, Scutum, Sagittarius to Scorpio, where it is partially united with the broken western stream. More than 100 years ago, Sir John Herschel at the Cape, "rummaging the recesses" of Scorpio, found it full of beautiful globular clusters. It was somewhere here that the elder Herschel found the 'hole' in the heavens, which modern astronomers now recognize as one of the numerous dark nebulæ found in the Milky Way. The Pleiades rise in the late evening as the precursor of winter nights and of brilliant stars in their well-known constellations.

\section{Announcements}

Dr. Paul C. Mangelsdorf, vice-director of the Texas Agricultural Experiment Station, has been appointed professor of botany in Harvard University and assistant director of the Botanical Museum.

Dr. William Cramer, British delegate to the International Cancer Congress at Atlantic City in September 1939 and for more than twenty-five years a member of the Imperial Cancer Research Fund, London, has joined the staff of the Barnard Free Skin and Cancer Hospital in St. Louis.

A FURTHER modification in the terms on which enemy aliens can be released from internment was announced by Sir John Anderson in the House of Commons on August 23. In the White Paper setting out the conditions of release, scientific workers and others with academic qualifications were to be granted release if national work in their special fields was available for them. This qualification is now to be removed, on the recommendation of the Asquith Committee, which pointed out that "the benefits of science and learning were often indirect rather than direct". 